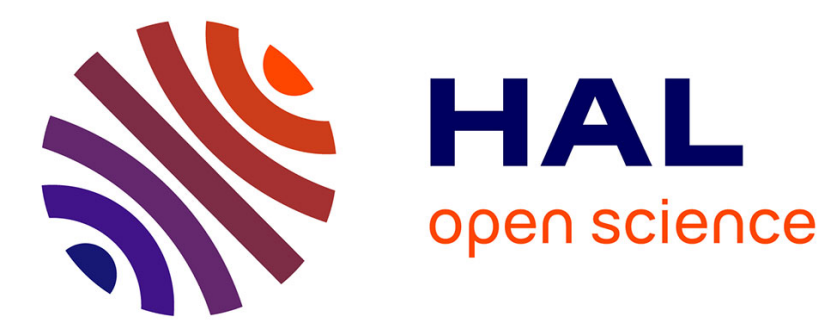

\title{
Hedgehog trafficking, cilia and brain functions.
}

Martial Ruat, Hermine Roudaut, Julien Ferent, Elisabeth Traiffort

\section{To cite this version:}

Martial Ruat, Hermine Roudaut, Julien Ferent, Elisabeth Traiffort. Hedgehog trafficking, cilia and brain functions.. Differentiation, 2012, 83 (2), pp.S97-104. 10.1016/j.diff.2011.11.011 . hal-00683601

\section{HAL Id: hal-00683601 https://hal.science/hal-00683601}

Submitted on 7 Apr 2021

HAL is a multi-disciplinary open access archive for the deposit and dissemination of scientific research documents, whether they are published or not. The documents may come from teaching and research institutions in France or abroad, or from public or private research centers.
L'archive ouverte pluridisciplinaire HAL, est destinée au dépôt et à la diffusion de documents scientifiques de niveau recherche, publiés ou non, émanant des établissements d'enseignement et de recherche français ou étrangers, des laboratoires publics ou privés. 


\title{
Hedgehog trafficking, cilia and brain functions
}

\author{
Martial Ruat*, Hermine Roudaut, Julien Ferent, Elisabeth Traiffort

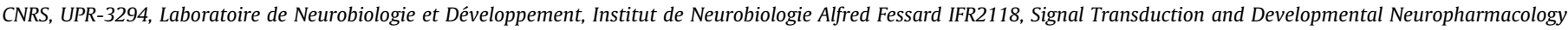 \\ Team, 1 avenue de la Terrasse, F-91198 Gif-sur-Yvette, France
}

The primary cilium has recently emerged as an important center for transduction of the Sonic Hedgehog (Shh) signal. Genetic studies have shown that Shh signaling at the level of primary cilia is essential for patterning the ventral neural tube and regulating adult stem cells. Some defects observed in human diseases and resulting from mutations affecting the organization of the primary cilium have been attributed to defective Shh signaling. The recent development of Shh pathway inhibitors for treating tumors linked to perturbations of Shh signaling has fostered studies to understand their mechanism of action in Shh receptor complex trafficking at the primary cilium.

\section{Introduction}

The Sonic Hedgehog (Shh) signaling pathway is well known for its roles in patterning and growth of brain structures during development (Dessaud et al., 2008; Varjosalo and Taipale, 2008). The early discovery of Shh expression throughout the adult rodent brain (Traiffort et al., 2010, 1998) has generated considerable interest and novel functions for this protein have progressively emerged (Borzillo and Lippa, 2005; Traiffort et al., 2010). The importance of Shh signaling in adult brain plasticity is demonstrated by its implication in neural stem cell maintenance in adult neurogenic niches (Han and Alvarez-Buylla, 2010; Suh et al., 2009). Humans affected by the Gorlin syndrome have inactivating mutations in the key Shh receptor Patched (Ptc), characterized as a negative regulator of Shh signaling. They display susceptibility to develop medulloblastoma, one of the most malignant brain tumors in childhood. As a consequence of these mutations, the Ptc-mediated inhibition exerted on the Smoothened (Smo) receptor, the main positive regulator of the pathway, is relieved, leading to the tumorigenic process. Thus, inhibiting the Shh signaling pathway by small molecule inhibitors has generated considerable interest for treating these tumors, and several inhibitors of Smo are currently being evaluated for treating medulloblastomas (Heretsch et al., 2010; Mas and Ruiz i Altaba, 2010; Scales and de Sauvage, 2009). The recent discovery that Shh signaling depends on primary cilia (Huangfu et al., 2003) has fostered studies aimed at characterizing the distribution and the regulation of the pathway at the level of this important signaling center (Goetz and Anderson, 2010; Louvi and Grove,

\footnotetext{
* Corresponding author.

E-mail address: ruat@inaf.cnrs-gif.fr (M. Ruat).
}

2011; Simpson et al., 2009). Genetic studies in mice showed that Shh signaling at the level of the primary cilium is essential for patterning of the ventral neural tube in the mouse embryo but also in the regulation of adult stem cells (Han and Alvarez-Buylla, 2010). In addition, some defects in human diseases known as ciliopathies and resulting from mutations affecting the organization of the primary cilia, have been attributed to defective Hedgehog (Hh) signaling (Goetz and Anderson, 2010). Here, we review the role of $\mathrm{Hh}$ signaling and trafficking at the primary cilium during brain development and in mature neural tissues. We also highlight its importance for treating brain tumors and understanding the complex traits of several human disorders linked to primary cilia defects.

\section{Transduction of Hh signaling at the primary cilium}

In vertebrates, the primary cilium is defined as a microtubulebased organelle of about 1-5 $\mu \mathrm{m}$ in length. It extends from the cell surface as a single, non motile, antenna-like structure and is present on most cell types in embryonic and adult tissues (Bettencourt-Dias et al., 2011; Louvi and Grove, 2011). The ciliary basal body is formed from the mother centriole and acts as a docking area for a large number of pericentriolar proteins. The axoneme, constituted by nine doublets of microtubules, extends from the basal body through the cilium. Between the basal body and the axoneme, the transition fibers create a permeable barrier between the cilium and the rest of the cell. Selective import or export of proteins between the cytoplasm and the cilium require intraflagellar transport (IFT) particles forming two complexes B and $A$, which use the anterograde kinesin-2 (also known as the Kif3 motor complex) and the retrograde dynein motors, respectively (Rosenbaum and Witman, 2002; Taschner et al., 2011). The 
primary cilium differs from the secondary motile cilia. In the latter, the axoneme contains an extra central pair of microtubules linked to the nine outer microtubule pairs. Intense genetic, molecular, biochemical and pharmacological studies have recently been conducted to understand its ultrastructure and its functions in the central nervous system (CNS). Notably, efforts have been made to identify components of signal transduction pathways that are present in this organelle. Trafficking of proteins involved in the Hh signaling pathway up and down the cilium in stem or precursor cells has rapidly emerged as a key step in neural development (Goetz and Anderson, 2010; Louvi and Grove, 2011).

Shh, Indian hedgehog, and Desert Hedgehog genes encode a family of secreted peptides with key roles in tissue patterning during embryogenesis. Their roles in adult neural tissues and the involvement of the associated signaling pathway in brain physiology and in pathologies are just beginning to be explored (Traiffort et al., 2010). These proteins mediate their action via a receptor complex associating two transmembrane proteins: Ptc, the Shh receptor, which displays a transporter-like structure, and Smo, a putative member of the $G$ protein-coupled receptor superfamily, which transduces the Shh signal downstream of Ptc. The repression exerted by Ptc on Smo is relieved when Shh binds Ptc and a complex signaling cascade is initiated leading to the activation of the transcription factors of the Gli family (Gli1-3) and to the transcription of target genes including Ptc and Gli1 themselves (Fig. 1) (Ruiz i Altaba et al., 2007). Activation of the canonical Shh pathway leads to the inhibition of Gli transcription factor processing into their transcriptional repressor forms and to the concomitant accumulation of their activator forms. Gli1 constitutes a convenient readout for pathway activation and amplifies the $\mathrm{Hh}$ response. Gli2 and Gli3 function mainly as transcriptional activator and repressor, respectively, even if both can show the opposite activity in specific contexts (Riobo and Manning, 2007; Ruiz i Altaba et al., 2007).

Besides the canonical Shh pathway, a non-canonical pathway has also been described. It induces synchronous $\mathrm{Ca}^{2+}$ spikes and IP3 transients at the neuronal primary cilium through the activation of Smo (Belgacem and Borodinsky, 2011). Several additional proteins such as the negative regulator Hedgehog-interacting protein (Hip), which is found in a soluble and membrane associated form in brain regions (Coulombe et al., 2004), the two cell surface immunoglobulin/fibronectin proteins, Boc and Cdo, and the growth arrest-specific 1 protein (Gas1) bind Hh proteins with high affinity, function as Shh coreceptors and promote Hh signaling according to unknown mechanisms (Varjosalo and Taipale, 2008; Allen et al., 2011). The structurally related Boc and Cdo are integral membrane proteins conserved from Drosophila to rodent whereas Gas1, a glycosylphosphatidylinositol anchored plasma membrane protein, is specific to Hh signaling in vertebrates. A likely model proposes that Gas1, Cdo and Boc form a physical complex with Ptc and function as essential coreceptors that mediate multiple cellular responses to Hh. However, this requirement of $\mathrm{Hh}$ coreceptors depends on the cell type and the stage of development (Allen et al., 2011; Izzi et al., 2011).

Smo, Ptc, Gli1-3 and the negative regulator Sufu have been detected at the primary cilium (Corbit et al., 2005; Haycraft et al., 2005; Huangfu and Anderson, 2006; Rohatgi et al., 2007; Roudaut et al., 2011). Shh has been identified close to the cilium base in target neural progenitors during active Shh signaling in the neural tube (Chamberlain et al., 2008). Ptc is proposed to be localized to the base of the cilium in the absence of its ligand and to inhibit signaling by preventing Smo localization to the cilium (Fig. 1). Upon ligand binding, simultaneous removal of Ptc and localization of Smo to cilia occur. $\beta$-arrestins might mediate Smo interaction with the Kif3a kinesin motor protein, regulating Smo localization to primary cilia (Kovacs et al., 2008; Rohatgi et al., 2007). Alternatively, Smo may
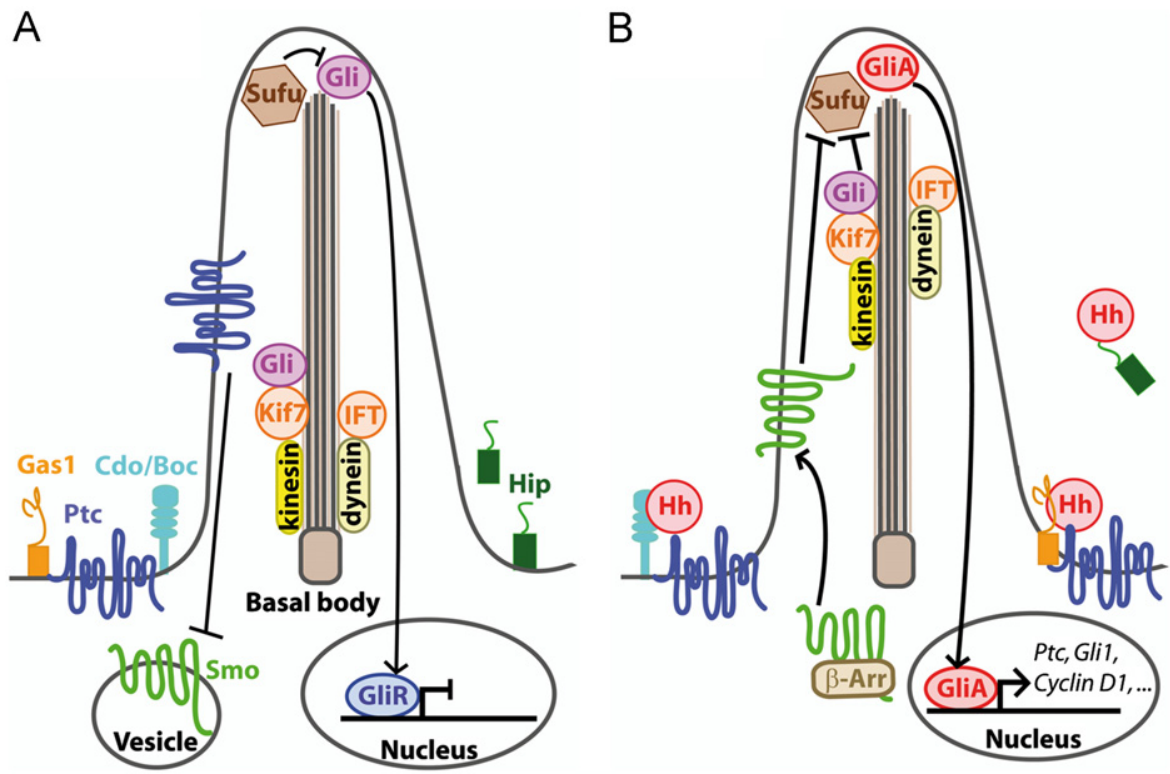

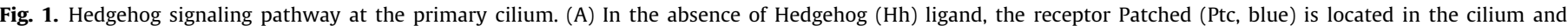

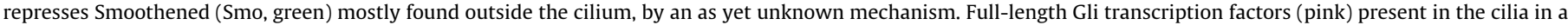

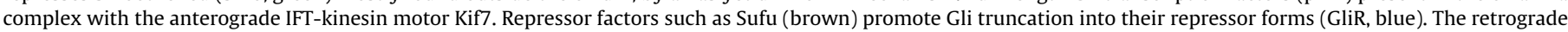

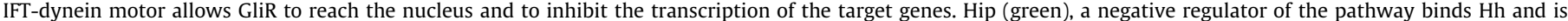

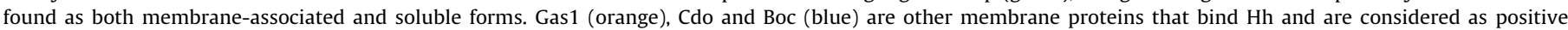

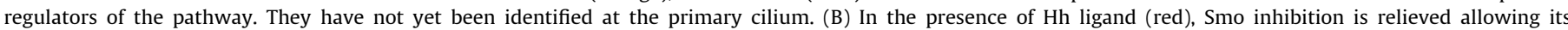

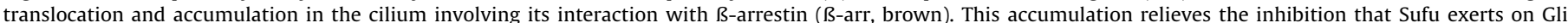

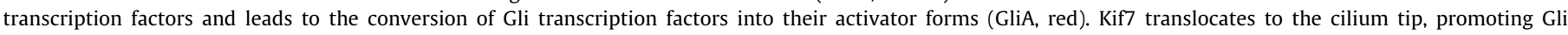

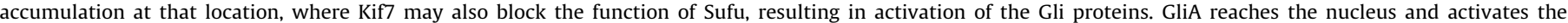
transcription of Hh target genes including Ptc and Gli1 themselves. 
move through a lateral transport pathway from the plasma membrane to the ciliary membrane (Milenkovic et al., 2009). Finaly, phosphorylation of mouse Smo carboxyl terminal tail by the serine/ threonine kinases GIRK2 and CK1 $\alpha$ was found to activate the receptor and promote its ciliary accumulation (Friedland-Little et al., 2011). Activation of Smo would then antagonize the activity of Sufu, which negatively regulates the Gli transcription factors (Fig. 1). The kinesin Kif7, a vertebrate homolog of Drosophila Costal2 regulating the activity of Cubitus interruptus (the homolog of the Gli transcription factors) (Ayers and Therond, 2010; Ingham et al., 2011 ), is proposed to play a major role for tethering the components of the Hh pathway at the primary cilium. Kif7 motor domain retains the sequences characteristic of kinesin motors suggesting it may behave as an anterograde motor protein. Kif7 would act downstream of Smo and upstream of Gli2. Its activity depends on the presence of the primary cilium and it has both negative and positive roles in Shh signal transduction. In the absence of Shh, Kif7 is localized to the cilium base where it forms a complex in particular with Gli proteins and promotes processing of Gli repressor forms. Upon ligand stimulation, Kif7 translocates to the cilium tip and would block Sufu, resulting in the accumulation and activation of the Gli proteins (Endoh-Yamagami et al., 2009; Liem et al., 2009). Interestingly, both Gli2 and Smo were found to require the retrograde motor dynein for exiting the cilia (Kim et al., 2009).

\section{Hh ciliary dysfunction and human diseases affecting neural tissues}

Recent studies have investigated the link between the dysfunction of primary cilia and Hh signaling in human ciliopathies and in related mouse models (Simpson et al., 2009) (Table 1). Several components of the mouse IFT machinery required for the assembly and maintenance of cilia were reported from a mutant screen to be essential for the specification of Shh-dependent ventral cell types in the neural tube. They include the IFTB complex components IFT172, IFT88 and the IFT-dedicated retrograde motor DYNC2H1. Disruption of the kinesin-2 motor (Kif3a-null embryos) also result in similar defects in Shh-dependent neural patterning (Huangfu and Anderson, 2005; Huangfu et al., 2003; May et al., 2005). IFT proteins presumably act downstream of Ptc and Smo and upstream of the Gli factors as suggested by genetic studies (Huangfu and Anderson, 2005). The activator or repressor forms of Gli proteins depend on IFT. Loss of Shh signaling in the neural tube of IFT mouse mutants such as ift 88 mutant might be linked to the absence of Gli activator forms in the cilia.
Mutations in several basal body proteins also indicate that cilia are required for Hh signaling. For instance, the chick Talpid3 mutant displaying a mutated centrosomal protein, causes a disrupted cilium, alters $\mathrm{Hh}$ signaling and is associated with developmental defects consistent with disrupted Hh pathway (Davey et al., 2007; Yin et al., 2009). In the same line, mouse mutants for Ofd1 (oral-facial-digital syndrome), Ftm (fantom) or Mks1 (Meckel syndrome type 1) display abnormal or absent cilia, and Hh signaling defects (Goetz and Anderson, 2010).

More recent genetic studies of gene mutations in human ciliopathies and in several human disorders have identified other proteins involved in cilium function (see Table 1). Thus, these mutations affect Hh signaling and are associated to the developmental defects that are also observed in their mouse mutant counterpart (see for review Goetz and Anderson, 2010). For example, mutations in the Kif7 gene have been associated with the Joubert syndrome and two developmental disorders called fetal hydrolethalus and acrocallosal syndromes (Table 1; Dafinger et al., 2011; Putoux et al., 2011). When Kif7 expression is reduced by siRNA in cell lines, the number of cells expressing primary cilia is reduced. An abnormal centrosomal duplication and fragmentation of the Golgi network presumably due to alteration of microtubule stability is also observed (Dafinger et al., 2011). Consistent with a role of Kif7 in Hh signaling acting at the primary cilium, the Gli transcription factors are misregulated in tissues from Kif7 mutated fetuses. In addition, the pathogenic potential of the Kif7 mutant was demonstrated using in vivo complementation approach to rescue morphant phenotypes with human mRNA (Putoux et al., 2011).

Mutations of Shh have been also associated with holoprosencephaly, a rare disorder characterized by a large spectrum of brain and cranio-facial anomalies. Functional analysis of eleven of these mutations has shown that the production of the active fragment of Shh is dramatically impaired in eight of them, but not or slightly affected for three others (Traiffort et al., 2004). It would be interesting to investigate whether these three last mutations are affecting Shh targeting to the cilium base (Chamberlain et al., 2008) thus resulting to Shh signaling impairment. Further studies are necessary to demonstrate whether pharmacological manipulating of the Hh pathway (Fig. 2) might be of therapeutic value for these various syndromes.

\section{Cilia, Hh signaling and hippocampal development}

Recent advances in adult neurogenesis have highlighted the capacity of the brain to generate new neurons throughout adult

Table 1

Ciliary components associated with Hedgehog signaling impairment and identified in human disorders.

\begin{tabular}{|c|c|c|c|}
\hline Function & $\begin{array}{l}\text { Mouse gene } \\
\text { identified }\end{array}$ & $\begin{array}{l}\text { Hh signaling } \\
\text { impairment }\end{array}$ & Pathologies \\
\hline Small GTPase & Arl13b & Decreased & $\mathrm{JS}^{\mathrm{a}}$ \\
\hline Basal body proteins & Ftm, Mks1, Ofd1, Evc & Decreased & EVC $^{\mathrm{a}}$, JS type $\mathrm{B}^{\mathrm{a}}, \mathrm{MKS}^{\mathrm{a}}, \mathrm{OFD}^{\mathrm{a}}$ \\
\hline B9 domain-containing proteins & B9D2 & Decreased & MKS \\
\hline Centrosomal protein & Stil & Decreased & Primary microcephaly ${ }^{\mathrm{a}}$ \\
\hline Kinesin-like protein & Kif7 & Decreased & JS, Fetal hydrolethalus, Acrocallosal syndroms \\
\hline Kinesin anterograde subunit & Kif3a & Decreased & nd $^{\mathrm{a}}$ \\
\hline Dynein retrograde motor subunit & Dync2h1 & Decreased & JATD $^{\mathrm{a}}$ \\
\hline IFT particles involved in retrograde movement (IFTA) & Ift 139, Ift 122 & Increased & Nephronophthisis, JATD or nd $^{\mathrm{a}}$ \\
\hline IFT particles involved in anterograde movement (IFTB) & Ift172, Ift52, Ift57, Ift 88 & Decreased & VACTERL-H mouse model or nd $^{\mathrm{a}}$ \\
\hline PCP proteins & Fuz, Intu & Decreased & $\mathrm{nd}^{\mathrm{a}}$ \\
\hline
\end{tabular}

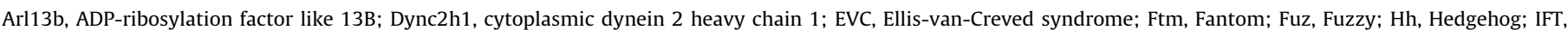

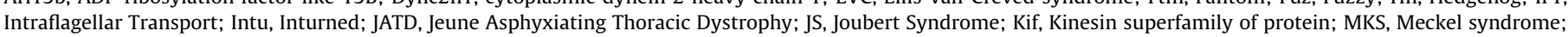

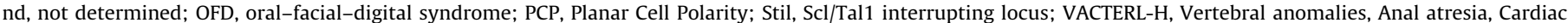
malformations, Tracheo-Eosophageal fistula, Renal and Limb malformations with Hydrocephalus.

a See Davis et al. (2011), Dowdle et al. (2011), Friedland-Little et al. (2011), Goetz and Anderson (2010), and Putoux et al. (2011). 
A

SANT-1

GDC-0449

MRT-83 Cyclopamine Ptc M2 mutation

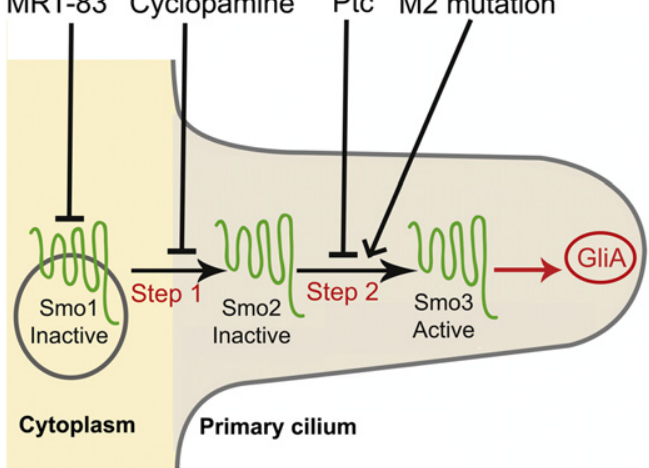

B

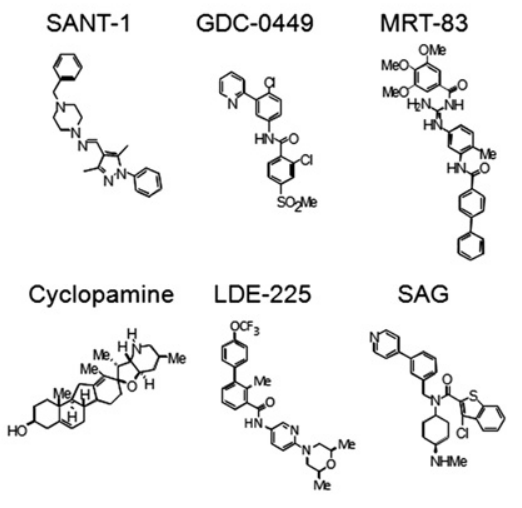

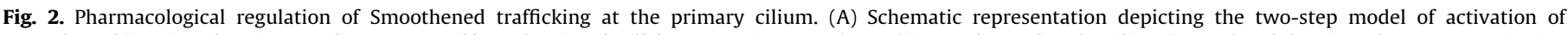

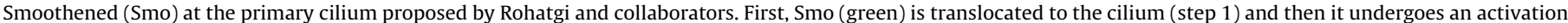

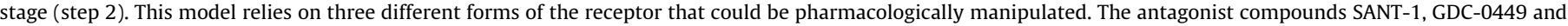

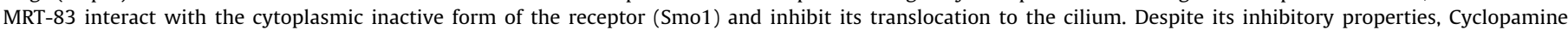

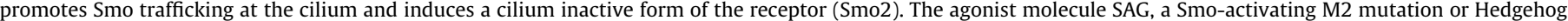

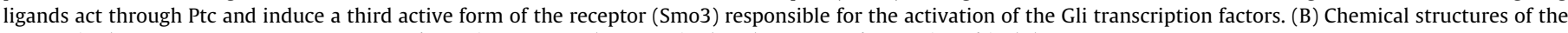
antagonist (SANT-1, GDC-0449, MRT-83, Cyclopamine, LDE-225) or agonist (SAG) compounds mentioned in (A).

life. Stem cells have been characterized in several regions of the adult brain including the subventricular zone (SVZ) of the lateral ventricles and the subgranular zone (SGZ) of the dentate gyrus (Kriegstein and Alvarez-Buylla, 2009; Zhao et al., 2008). Both neurogenic niches contain astrocytes displaying features of slowdividing adult neural stem cells that give rise to transit-amplifying cells, the primary precursors of migrating neuroblasts. The SVZ and the SGZ provide new neurons fully integrated into the granular- and glomerular cell layers of the olfactory bulbs and into the granular cell layer of the hippocampus, respectively. In defined pathological conditions, newly generated cells deviate from their normal destination and migrate towards the injured tissue.

The identification of a specific Shh pathway in the adult brain including the characterization of cells expressing Shh and its receptor components (Coulombe et al., 2004; Loulier et al., 2005; Traiffort et al., 1999) has paved the way to identify its potential roles in the normal and diseased brain. The pathway is active in the SVZ and controls the maintenance of stem and precursor cells (Ahn and Joyner, 2005; Angot et al., 2008; Charytoniuk et al., 2002b; Machold et al., 2003; Palma et al., 2005). In the hippocampus, an increase in the number of proliferating cells is induced in the SGZ by local adeno-associated viral vector delivery of Shh or oral administration of an Hh agonist. Conversely, treatment with the Smo inhibitor Cyclopamine reduced hippocampal neural progenitor proliferation in vivo (Banerjee et al., 2005; Lai et al., 2003; Machold et al., 2003). These data identified for the first time Shh as a regulator of adult hippocampal neural stem cells. Shh signaling acting through the primary cilia was then proposed to display a critical role in the expansion and establishment of postnatal hippocampal progenitors. Mice lacking Smo in Glial Fibrillary Acidic Protein (GFAP)-positive neural precursor cells show a defect in hippocampal neurogenesis reflected by a very small dentate gyrus, a markedly reduced proliferation and few newly generated neurons. This phenotype is close to the one observed in mice lacking the kinesin Kif3a (Takeda et al., 1999) in GFAP-positive cells, which display defective ciliogenesis, impairment of Shh signaling in granule neuron precursors and no generation of radial astrocytes that function as the SGZ stem cells (Han et al., 2008). Overexpression of an oncogenic form of Smo (SmoM2) in hippocampal granule neuron precursors does not result in tumor formation but nevertheless to a clear increase of granule neuron precursors (Han et al., 2008). In these cells, SmoM2 is localized to primary cilia, in agreement with its previously found subcellular localization in fibroblasts (Rohatgi et al., 2009). Such an effect was not observed in Kif3a mutant. Thus, correct Shh signaling through Smo is essential for hippocampal stem cell development. In the Stumpy mutant lacking ciliary axonemes in the hippocampus (Breunig et al., 2008; Town et al., 2008), improper Gli3 processing was also associated with the loss of cilia. The thinner dentate granule cell layer observed in these animals was linked to deficiency in neural stem cells and cell cycle exit, presumably related to a decrease of Hh signaling at the primary cilia. Among the Gli transcription factors, Gli1 was found to be the only one to be transcriptionally induced following Shh pathway activation in the SGZ and was required for the self-renewal of postnatal neural stem cells (Galvin et al., 2008). In this area, Gli1 expression is associated with the upregulation of genes not previously identified as Gli1 transcriptional targets such as proapoptotic genes and genes governing the G2-M transition. This might be related to the unique ability of neural stem cells to maintain tight regulation over cell cycle progression. Although hippocampal development in embryos and neural stem cell maintenance require Sox2dependent regulation of Shh, this type of regulation remains to be determined in adult hippocampal neural stem cells (Favaro et al., 2009).

When adult neurogenesis is constantly decreased by conditional ablation of primary cilia in adult GFAP_positive neural stem cells, a delay in spatial learning and alteration of spatial novelty recognition were observed (Amador-Arjona et al., 2011). However, it is not yet known whether cognitive deficits observed in ciliopathies are related in some aspects to alteration of $\mathrm{Hh}$ signaling at the primary cilia. The distribution of Smo protein to hippocampal mossy fibers (Masdeu et al., 2007) and its proposed regulation by synaptic activity involving glutamatergic transmission suggest additional roles for Hh signaling in the control of hippocampal functions (Banerjee et al., 2005; Petralia et al., 2011).

\section{Cilia, Hh signaling and cerebellum development}

Granule neurons in the cerebellum represent the most abundant neurons in the adult brain and arise from granule cell 
precursors (GCPs) located in the rhombic lip. From this germinal center, GCPs migrate into the external granule cell layer (EGL) and proliferate during the first two weeks after birth to produce granule neurons. In the postnatal maturing cerebellum, Shh from the Purkinje cells is a potent mitogen for GCPs (Traiffort et al., 2010). This effect presumably occurs through the induction of one of its direct targets, the proto-oncogene $N$-myc 1 mediating cell proliferation via cyclin D1 and D2 (Knoepfler and Kenney, 2006). As previously mentioned in the SGZ of the dentate gyrus, the primary cilium is required for Shh-induced expansion of GCPs. The loss of primary cilium observed in the conditional ablation of the kinesin Kif3a severely disrupts cerebellar development from birth. This effect is associated with a great depletion of the granule cell population in the EGL linked to the down regulation of Shh target genes Gli1 and cyclin D1 (Spassky et al., 2008). These observations may explain the hypoplasia of cerebellar vermis observed in Joubert and Bardet-Biedl syndromes, two ciliopathic genetic disorders associated with defective primary cilia and also characterized by breathing abnormalities, ataxia, developmental delay, hydrocephalus, anatomical anomalies of the cerebral cortex or retinal dystrophy (Joubert syndrome) and obesity, mental retardation, polydactyly, gonadal malformation, retinal dystrophy, renal dysfunction (Bardet-Biedl syndrome) (Louie and Gleeson, 2005). In addition, the loss of Smo in the GCPs mimics the phenotype of Kif3a deficient mice. However in the Smo mutants, both the rate of proliferation and the defects in cerebellar foliation are more severely disrupted. This was related to the persistence of a cilia dependent-repressor activity (probably Gli3), leading to a more severe proliferation defect. In conditional Kif3a mutants, the loss of repressor (Gli3) as well as activators (Gli1, 2) leads to less severe proliferation defects (Spassky et al., 2008).

Other components of the Hh pathway have been identified at the cilia of GCPs. A tagged form of Smo (Smo-HA) was found targeted to the primary cilia of cultured GCPs identified with antiadenylate cyclase III, a cilium shaft marker of neurons or related cells. Interestingly, the $\mathrm{G}_{\alpha i 2}$ and $\mathrm{G}_{\alpha i 3}$ subunits of $\mathrm{G}$ proteins that mediate a decrease in cAMP through inhibition of adenylate cyclase, were also located to the primary cilia when expressed in GCP cultures. The transcripts of $\mathrm{G}_{\alpha i 2}$ and $\mathrm{G}_{\alpha i 3}$ are observed in the outer EGL where proliferation occurs and silencing these genes is accompanied by a significant decrease of Shh-mediated GCP proliferation. Following these observations, it has been proposed that the proliferative effects of Shh on GCPs are mediated by Smo trafficking to the primary cilia involving $G_{\alpha i 2}$ and $\mathrm{G}_{\alpha i 3}$ (Barzi et al., 2011). Investigating whether Boc and Gas1, which are absolutely required for Shh-mediated GCP proliferation (Izzi et al., 2011), are expressed at the primary cilia should be an interesting further objective.

Impairment of neurogenesis during brain development has been proposed to be associated with mental retardation in Down syndrome (DS). Abnormal Shh signaling in the cerebellum of a mouse model for DS (the Ts65Dn mouse) (Roper et al., 2006) has been linked to the increase of Ptc expression, which would promote the expression of a transcription-promoting fragment of the amyloid precursor protein (AICD) (Trazzi et al., 2011). This latter study argues that the trisomic gene APP is involved in the impairment of neurogenesis in DS. This effect would be mediated through an AICD-dependent up-regulation of Ptc leading to severe deregulation of Hh signaling. However, whether these effects are linked to abnormal Hh signaling in primary cilia is not known.

\section{Astrocytes, cilia and Hh signaling}

Astrocytes play diverse essential roles in CNS during embryogenesis through regulation of synapse formation and function as well as by promoting dendritic spine maturation. In adulthood, they are proposed as key elements in synaptic transmission (Stipursky et al., 2011). Several studies indicate that Hh signaling is active in astrocytes both during development and in the more mature brain. It is responsible for the proliferation of astrocyte precursors in the developing chick optic nerve (Wallace and Raff, 1999) and regulates the expression of the transcription factor Pax2 implicated in astrocyte differentiation in the mouse retina (Sehgal et al., 2009). In the developing cerebellum, Shh from Purkinje neurons has been proposed to stimulate differentiation of Bergmann glia (Dahmane and Ruiz-i-Altaba, 1999). Astrocytes in primary culture have been shown to respond to both Hh proteins and to a Smo agonist leading to the transcription of $\mathrm{Hh}$ target genes (Atkinson et al., 2009). In the mature brain, Shh expressed by neurons including a subpopulation of GABAergic neurons in the forebrain (Charytoniuk et al., 2002a; Ihrie et al., 2011; Traiffort et al., 2001) regulates distinct populations of astrocytes (Garcia et al., 2010).

Glial (GFAP-positive) cells also express a primary cilia as shown by a small extracellular projection stained with antiadenylate cyclase type III antibody in rat and human cerebral cortex (Bishop et al., 2007; Doetsch et al., 1999; Yoshimura et al., 2011). Astrocytes in primary culture also displayed a primary cilium with all the structural hallmarks such as $9+0$ axonemal arrangement and a pair of centrioles at its base. In these cells, the endogenous pattern of localization of Ptc and Smo differs: Smo is found in a diffuse manner in the shaft of the primary cilia whereas Ptc accumulates at their base. This pattern of localization is similar to that one previously reported in human embryonic stem cells (Kiprilov et al., 2008) and is consistent with the model proposed for the dynamics of Hh signaling machinery (Rohatgi et al., 2007). Overexpression of Smo-GFP showed a specific targeting to primary cilia of these cultured astrocytes and activation of the Hh pathway was found to regulate the survival of these cells under stressed conditions (Yoshimura et al., 2011). Further work is needed to determine whether Hh signaling at the primary cilium of astrocytes is also implicated in cell survival after external insults in vivo.

\section{Cilia and Hh signaling in brain tumors}

Abnormal proliferation of cerebellar GCPs are associated with the development of medulloblastoma. These tumors were initially considered as $\mathrm{Hh}$ ligand-independent since aberrant signaling activation is linked to pathway-activating mutations in Ptc, Sufu or Smo (Scales and de Sauvage, 2009). Humans affected by the Gorlin syndrome display a higher incidence of medulloblastomas. Gorlin syndrome is an autosomal dominantly inherited disorder characterized by Ptc inactivating mutations that results in numerous basal cell carcinomas as well as a number of other facial and skeletal anomalies. The tumor formation is related to gene silencing induced by methylation of the Ptc promoter identified in mice but not in humans (Pritchard and Olson, 2008). However, several other pathways are presumably involved in regulating Hh-dependent formation of medulloblastoma such as the insulinlike growth factor pathway in Ptc heterozygous mice (Corcoran et al., 2008; Parathath et al., 2008). Interestingly, brain tumor stem cells derived from medulloblastoma occurring in Ptc heterozygous mice, have markedly higher basal Gli1 expression than normal stem cells. They do not undergo apoptosis but their proliferation rate is higher. This suggests a deficit in the protective mechanisms that lead non malignant stem cells to restrain hyperproliferation in the context of potentially transforming mitogenic signals (Galvin et al., 2008). 
Interestingly, primary cilia can both mediate and suppress Hhdependent tumorigenesis depending on the underlying oncogenic events, which may include constitutively active forms of Smo (SmoM2) or Gli2 (Gli2 $\Delta$ N) (Han et al., 2009; Wong et al., 2009). The constitutive localization of SmoM2 to the cilia, where it activates Gli2 and inhibits Gli3 repressor formation, accounts for the tumorigenic process. Therefore, the absence of cilia impedes SmoM2-mediated activation of downstream pathway. On the contrary, the constitutive activity of Gli $2 \Delta \mathrm{N}$ is independent of primary cilia. Nevertheless, when the cilia are present, mice expressing Gli2 $\Delta \mathrm{N}$ mutant do not develop medulloblastoma possibly due to the presence of Gli3 repressor. In the absence of cilia, Gli3 repressor is not generated and consequently Gli2 $\Delta \mathrm{N}$ induces medulloblastoma. The presence of primary cilia in specific variants of human medulloblastomas is also informative from a therapeutic point of view. Thus, ciliated medulloblastomas with high $\mathrm{Hh}$ signaling might be responsive to treatments that target the primary cilium (Han et al., 2009). Smo activation and its regulation by Hh signaling and by small molecules at the level of the primary cilium have been proposed as a key step in tumorigenesis-dependent processes but are still not sufficiently studied (Scales and de Sauvage, 2009).

\section{Smo trafficking at the primary cilia is regulated by $\mathrm{Hh}$ inhibitors}

Cyclopamine and several other small-molecule inhibitors of the Hh pathway (Fig. 2B) have been developed and proposed for the treatment of cancers associated with dysfunctions of $\mathrm{Hh}$ signaling. Most of these molecules, but not all, target Smo (Heretsch et al., 2010; Scales and de Sauvage, 2009). Among them, Cur61414 or HhAntag691 have been shown to induce remission in animal models of medulloblastoma. Recently, clinical trials for treating basal cell carcinoma and medulloblastoma in human have been conducted with the small molecule GDC-0449, which displays nanomolar potency for inhibiting Smo (Scales and de Sauvage, 2009). However, such molecules may have some limitations associated with Smo mutations leading to treatment resistance. This has recently been observed for a patient affected by a metastatic medulloblastoma refractory to multiple therapies. Despite an initially rapid tumor regression, the treated patient progressively developed a drug resistance, due to an acquired Smo mutation disrupting the ability of GDC-0449 to bind Smo (Rudin et al., 2009). A Smo mutation occurring at a homologous position in mouse Smo was also observed in a GDC-0449-resistant mouse model of medulloblastoma (Yauch et al., 2009). The development of resistances was also observed in mice exhibiting medulloblastoma treated by the Smo inhibitor LDE-225 also used in clinical trials (Buonamici et al., 2011). These resistances were associated with amplification of the transcription factor Gli2 linked to Hh signaling, to activating Smo mutations and possibly to up-regulation of the phosphatidylinositol 3-kinase signaling pathway. The Smo antagonist MRT-83 blocks Hh signaling in mouse SVZ in vivo and Smo trafficking to the primary cilium like GDC-0449 and LDE-225 (Roudaut et al., 2011; H.R. and MR, unpublished work) but its ability to block medulloblastoma has not been yet reported.

It has been proposed that Smo activation first requires its translocation to the primary cilium, and then is followed by the proper activation step (Fig. 2A). Consequently, Smo inhibitors have been classified into at least two families of compounds. SANT1-like molecules that would block Smo trafficking to the primary cilium and Cyclopamine-like molecules that would affect Smo activation process within the cilium (Rohatgi et al., 2009). The SmoM2 mutation has been associated with basal cell carcinoma and SmoM2 protein is equally distributed in the cytoplasm and in the primary cilium of transfected cells (Rohatgi et al., 2009). Interestingly, the mutant protein is less sensitive to Cyclopamine than wild type Smo, whereas SANT1 inhibits both proteins with similar potency (Chen et al., 2002). It has been anticipated that SmoM2-like mutations that might arise from drug treatment in the clinic will therefore be more sensitive to the SANT1-like family of molecules than to the Cyclopaminelike family of molecules (Scales and de Sauvage, 2009). Further studies should clarify the molecular and biochemical mechanisms underlying the resistance to Smo inhibitors, particularly at the level of the primary cilium in normal and cancer cells.

\section{Conclusions}

The functional roles of the Shh signaling pathway in the developing and adult CNS range from regulation of stem and precursor cells to the modulation of electrophysiological activity of neurons (Bezard et al., 2003; Pascual et al., 2005). Increasing evidences have shown that Shh signaling depends on the primary cilium. Progress has still to be made for further understanding the molecular and biochemical events controlling Hh pathway trafficking at this important signaling center. Besides genetic studies aimed at characterizing Sh signaling defects in human diseases linked to alteration of the primary cilium biology, pharmacological approaches using small molecules inhibitors or activators of the pathway should unraveled novel properties of this trafficking. Such studies may provide novel data for considering Shh signaling as playing an active role in the tissue-repair process in brain diseases (Loulier et al., 2006). In this context, the development of drug-like Hh agonists and antagonists and the understanding of their mechanism of action including at the primary cilium, is of great interest not only for treating brain tumors but also for developing novel therapies.

\section{Acknowledgment}

We thank S. O'Reagan for her comments on the manuscript. This work was supported by La Ligue Contre Le Cancer to M.R. (comité de l'Essonne) and by a fellowship from DGA to J.F.

\section{References}

Ahn, S., Joyner, A.L., 2005. In vivo analysis of quiescent adult neural stem cells responding to Sonic Hedgehog. Nature 437, 894-897.

Allen, B.L., Song, J.Y., Izzi, L., Althaus, I.W., Kang, J.S., Charron, F., Krauss, R.S. McMahon, A.P., 2011. Overlapping roles and collective requirement for the coreceptors GAS1, CDO, and BOC in SHH pathway function. Developmental Cell 20, 775-787.

Amador-Arjona, A., Elliott, J., Miller, A., Ginbey, A., Pazour, G.J., Enikolopov, G., Roberts, A.J., Terskikh, A.V., 2011. Primary cilia regulate proliferation of amplifying progenitors in adult hippocampus: implications for learning and memory. The Journal of Neuroscience 31, 9933-9944.

Angot, E., Loulier, K., Nguyen-Ba-Charvet, K.T., Gadeau, A.P., Ruat, M., Traiffort, E. 2008. Chemoattractive activity of sonic hedgehog in the adult subventricular zone modulates the number of neural precursors reaching the olfactory bulb. Stem Cells 26, 2311-2320.

Atkinson, P.J., Dellovade, T., Albers, D., Von Schack, D., Saraf, K., Needle, E. Reinhart, P.H., Hirst, W.D., 2009. Sonic Hedgehog signaling in astrocytes is dependent on p38 mitogen-activated protein kinase and G-protein receptor kinase 2. Journal of Neurochemistry 108, 1539-1549.

Ayers, K.L., Therond, P.P., 2010. Evaluating Smoothened as a G-protein-coupled receptor for Hedgehog signalling. Trends in Cell Biology 20, 287-298.

Banerjee, S.B., Rajendran, R., Dias, B.G., Ladiwala, U., Tole, S., Vaidya, V.A., 2005 Recruitment of the Sonic Hedgehog signalling cascade in electroconvulsive seizure-mediated regulation of adult rat hippocampal neurogenesis. European Journal of Neuroscience 22, 1570-1580.

Barzi, M., Kostrz, D., Menendez, A., Pons, S., 2011. Sonic Hedgehog-induced proliferation requires specific Galpha inhibitory proteins. The Journal of Biological Chemistry 286, 8067-8074. 
Belgacem, Y.H., Borodinsky, L.N., 2011. Sonic Hedgehog signaling is decoded by calcium spike activity in the developing spinal cord. Proceedings of the National Academy of Sciences 108, 4482-4487.

Bettencourt-Dias, M., Hildebrandt, F., Pellman, D., Woods, G., Godinho, S.A., 2011 Centrosomes and cilia in human disease. Trends in Genetics 27, 307-315.

Bezard, E., Baufreton, J., Owens, G., Crossman, A.R., Dudek, H., Taupignon, A Brotchie, J.M., 2003. Sonic Hedgehog is a neuromodulator in the adult subthalamic nucleus. FASEB Journal 17, 2337-2338.

Bishop, G.A., Berbari, N.F., Lewis, J., Mykytyn, K., 2007. Type III adenylyl cyclase localizes to primary cilia throughout the adult mouse brain. The Journal of Comparative Neurology 505, 562-571.

Borzillo, G.V., Lippa, B., 2005. The Hedgehog signaling pathway as a target for anticancer drug discovery. Current Topics in Medicinal Chemistry 5, 147-157.

Breunig, J.J., Sarkisian, M.R., Arellano, J.I., Morozov, Y.M., Ayoub, A.E., Sojitra, S. Wang, B., Flavell, R.A., Rakic, P., Town, T., 2008. Primary cilia regulate hippocampal neurogenesis by mediating sonic hedgehog signaling. Proceedings of the National Academy of Sciences 105, 13127-13132.

Buonamici, S., Williams, J., Morrissey, M., Wang, A., Guo, R., Vattay, A., Hsiao, K., Yuan, J., Green, J., Ospina, B., Yu, Q., Ostrom, L., Fordjour, P., Anderson, D.L. Monahan, J.E., Kelleher, J.F., Peukert, S., Pan, S., Wu, X., Maira, S.M., GarciaEcheverria, C., Briggs, K.J., Watkins, D.N., Yao, Y.M., Lengauer, C., Warmuth, M., Sellers, W.R., Dorsch, M., 2011. Interfering with resistance to smoothened antagonists by inhibition of the PI3K pathway in medulloblastoma. Science Translational Medicine 2 (51ra70).

Chamberlain, C.E., Jeong, J., Guo, C., Allen, B.L., McMahon, A.P., 2008. Notochordderived Shh concentrates in close association with the apically positioned basal body in neural target cells and forms a dynamic gradient during neura patterning. Development 135, 1097-1106.

Charytoniuk, D., Porcel, B., Rodriguez Gomez, J., Faure, H., Ruat, M., Traiffort, E. 2002a. Sonic Hedgehog signalling in the developing and adult brain. Journal of Physiology (Paris) 96, 9-16.

Charytoniuk, D., Traiffort, E., Hantraye, P., Hermel, J.M., Galdes, A., Ruat, M., 2002b. Intrastriatal Sonic Hedgehog injection increases patched transcript levels in the adult rat subventricular zone. The Journal of Neuroscience 16, 2351-2357.

Chen, J.K., Taipale, J., Cooper, M.K., Beachy, P.A., 2002. Inhibition of Hedgehog signaling by direct binding of cyclopamine to Smoothened. Genes and Development 16, 2743-2748.

Corbit, K.C., Aanstad, P., Singla, V., Norman, A.R., Stainier, D.Y., Reiter, J.F. 2005. Vertebrate Smoothened functions at the primary cilium. Nature 437, 1018-1021.

Corcoran, R.B., Bachar Raveh, T., Barakat, M.T., Lee, E.Y., Scott, M.P., 2008. Insulinlike growth factor 2 is required for progression to advanced medulloblastoma in patched 1 heterozygous mice. Cancer Research 68, 8788-8795.

Coulombe, J., Traiffort, E., Loulier, K., Faure, H., Ruat, M., 2004. Hedgehog interacting protein in the mature brain: membrane-associated and soluble forms. Molecular and Cellular Neuroscience 25, 323-333.

Dafinger, C., Liebau, M.C., Elsayed, S.M., Hellenbroich, Y., Boltshauser, E., Korenke G.C., Fabretti, F., Janecke, A.R., Ebermann, I., Nurnberg, G., Nurnberg, P., Zentgraf, H., Koerber, F., Addicks, K., Elsobky, E., Benzing, T., Schermer, B., Bolz, H.J., 2011 Mutations in KIF7 link Joubert syndrome with Sonic Hedgehog signaling and microtubule dynamics. The Journal of Clinical Investigation 121, 2662-2667.

Dahmane, N., Ruiz-i-Altaba, A., 1999. Sonic hedgehog regulates the growth and patterning of the cerebellum. Development 126, 3089-3100.

Davey, M.G., James, J., Paton, I.R., Burt, D.W., Tickle, C., 2007. Analysis of talpid3 and wild-type chicken embryos reveals roles for Hedgehog signalling in development of the limb bud vasculature. Developmental Biology 301 $155-165$.

Davis, E.E., Zhang, Q., Liu, Q., Diplas, B.H., Davey, L.M., Hartley, J., Stoetzel, C. Szymanska, K., Ramaswami, G., Logan, C.V., Muzny, D.M., Young, A.C., Wheeler D.A., Cruz, P., Morgan, M., Lewis, L.R., Cherukuri, P., Maskeri, B., Hansen, N.F. Mullikin, J.C., Blakesley, R.W., Bouffard, G.G., Gyapay, G., Rieger, S., Tonshoff, B. Kern, I., Soliman, N.A., Neuhaus, T.J., Swoboda, K.J., Kayserili, H., Gallagher, T.E., Lewis, R.A., Bergmann, C., Otto, E.A., Saunier, S., Scambler, P.J., Beales, P.L. Gleeson, J.G., Maher, E.R., Attie-Bitach, T., Dollfus, H., Johnson, C.A., Green, E.D. Gibbs, R.A., Hildebrandt, F., Pierce, E.A., Katsanis, N., 2011. TTC21B contributes both causal and modifying alleles across the ciliopathy spectrum. Nature Genetics 43, 189-196.

Dessaud, E., McMahon, A.P., Briscoe, J., 2008. Pattern formation in the vertebrate neural tube: a sonic Hedgehog morphogen-regulated transcriptional network. Development 135, 2489-2503.

Doetsch, F., Caille, I., Lim, D.A., Garcia-Verdugo, J.M., Alvarez-Buylla, A., 1999 Subventricular zone astrocytes are neural stem cells in the adult mammalian brain. Cell 97, 703-716.

Dowdle W.E Robinson, J.F. Kneist, A Sirerol-Piquer, M.S., Frints, S.G., Corbit, K.C. Zaghloul, N.A., van Lijnschoten, G., Mulders, L., Verver, D.E., Zerres, K., Reed, R.R., Attie-Bitach, T., Johnson, C.A., Garcia-Verdugo, J.M., Katsanis, N., Bergmann, C., Reiter, J.F., 2011. Disruption of a ciliary B9 protein complex causes Meckel syndrome. American Journal of Human Genetics 89, 94-110.

Endoh-Yamagami, S., Evangelista, M., Wilson, D., Wen, X., Theunissen, J.W., Phamluong, K., Davis, M., Scales, S.J., Solloway, M.J., de Sauvage, F.J., Peterson, A.S., 2009. The mammalian Cos2 homolog Kif7 plays an essential role in modulating Hh signal transduction during development. Current Biology 19, 1320-1326.

Favaro, R., Valotta, M., Ferri, A.L., Latorre, E., Mariani, J., Giachino, C., Lancini, C. Tosetti, S.K., Ottolenghi, S., Taylor, V., Nicolis, S.K., 2009. Hippocampal development and neural stem cell maintenance require Sox2-dependent regulation of Shh. Nature Neuroscience 12, 1248-1256.

Friedland-Little, J.M., Hoffmann, A.D., Ocbina, P.J., Peterson, M.A., Bosman, J.D., Chen, Y., Cheng, S.Y., Anderson, K.V., Moskowitz, I.P., 2011. A novel murine allele of Intraflagellar Transport Protein 172 causes a syndrome including VACTERL-like features with hydrocephalus. Human Molecular Genetics 20, 3725-3737.

Galvin, K.E., Ye, H., Erstad, D.J., Feddersen, R., Wetmore, C., 2008. Gli1 induces G2/ $M$ arrest and apoptosis in hippocampal but not tumor-derived neural stem cells. Stem Cells 26, 1027-1036.

Garcia, A.D., Petrova, R., Eng, L., Joyner, A.L., 2010. Sonic hedgehog regulates discrete populations of astrocytes in the adult mouse forebrain. The Journal of Neuroscience 30, 13597-13608.

Goetz, S.C., Anderson, K.V., 2010. The primary cilium: a signaling centre during vertebrate development. Nature Review Genetics 11, 331-344.

Han, Y.G., Alvarez-Buylla, A., 2010. Role of primary cilia in brain development and cancer. Current Opinion in Neurobiology 20, 58-67.

Han, Y.G., Kim, H.J., Dlugosz, A.A., Ellison, D.W., Gilbertson, R.J., Alvarez-Buylla, A., 2009. Dual and opposing roles of primary cilia in medulloblastoma development. Nature Medicine 15, 1062-1065.

Han, Y.G., Spassky, N., Romaguera-Ros, M., Garcia-Verdugo, J.M., Aguilar, A., Schneider-Maunoury, S., Alvarez-Buylla, A., 2008. Hedgehog signaling and primary cilia are required for the formation of adult neural stem cells. Nature Neuroscience 11, 277-284.

Haycraft, C.J., Banizs, B., Aydin-Son, Y., Zhang, Q., Michaud, E.J., Yoder, B.K., 2005. Gli2 and Gli3 localize to cilia and require the intraflagellar transport protein polaris for processing and function. PLoS Genetics 1, e53.

Heretsch, P., Tzagkaroulaki, L., Giannis, A., 2010. Modulators of the Hedgehog signaling pathway. Bioorganic and Medicinal Chemistry 18, 6613-6624.

Huangfu, D., Anderson, K.V., 2005. Cilia and Hedgehog responsiveness in the mouse. Proceedings of the National Academy of Sciences 102, 11325-11330.

Huangfu, D., Anderson, K.V., 2006. Signaling from Smo to Ci/Gli: conservation and divergence of Hedgehog pathways from Drosophila to vertebrates. Development 133, 3-14.

Huangfu, D., Liu, A., Rakeman, A.S., Murcia, N.S., Niswander, L., Anderson, K.V., 2003. Hedgehog signalling in the mouse requires intraflagellar transport proteins. Nature $426,83-87$

Ihrie, R.A., Shah, J.K., Harwell, C.C., Levine, J.H., Guinto, C.D., Lezameta, M., Kriegstein, A.R., Alvarez-Buylla, A., 2011. Persistent Sonic Hedgehog signaling in adult brain determines neural stem cell positional identity. Neuron 71, 250-262.

Ingham, P.W., Nakano, Y., Seger, C., 2011. Mechanisms and functions of Hedgehog signalling across the metazoa. Nature Review Genetics 12, 393-406.

Izzi, L., Levesque, M., Morin, S., Laniel, D., Wilkes, B.C., Mille, F., Krauss, R.S., McMahon, A.P., Allen, B.L., Charron, F., 2011. Boc and Gas1 each form distinct Shh receptor complexes with Ptch1 and are required for Shh-mediated cell proliferation. Developmental Cell 20, 788-801.

Kim, J., Kato, M., Beachy, P.A., 2009. Gli2 trafficking links Hedgehog-dependent activation of Smoothened in the primary cilium to transcriptional activation in the nucleus. Proceedings of the National Academy of Sciences 106, 21666-21671.

Kiprilov, E.N., Awan, A., Desprat, R., Velho, M., Clement, C.A., Byskov, A.G., Andersen, C.Y., Satir, P., Bouhassira, E.E., Christensen, S.T., Hirsch, R.E., 2008. Human embryonic stem cells in culture possess primary cilia with Hedgehog signaling machinery. The Journal of Cell Biology 180, 897-904.

Knoepfler, P.S., Kenney, A.M., 2006. Neural precursors cycling at Sonic speed: N-Myc Pedals, GSK-3 Brakes. Cell Cycle 5, 47-52.

Kovacs, J.J., Whalen, E.J., Liu, R., Xiao, K., Kim, J., Chen, M., Wang, J., Chen, W., Lefkowitz, R.J., 2008. Beta-arrestin-mediated localization of Smoothened to the primary cilium. Science $320,1777-1781$.

Kriegstein, A., Alvarez-Buylla, A., 2009. The glial nature of embryonic and adult neural stem cells. Annual Review of Neuroscience 32, 149-184.

Lai, K., Kaspar, B.K., Gage, F.H., Schaffer, D.V., 2003. Sonic Hedgehog regulates adult neural progenitor proliferation in vitro and in vivo. Nature Neuroscience 6, 21-27.

Liem Jr., K.F., He, M., Ocbina, P.J., Anderson, K.V., 2009. Mouse Kif7/Costal2 is a cilia-associated protein that regulates Sonic Hedgehog signaling. Proceedings of the National Academy of Sciences 106, 13377-13382.

Louie, C.M., Gleeson, J.G., 2005. Genetic basis of Joubert syndrome and related disorders of cerebellar development. Human Molecular Genetics 2, R235-R242.

Loulier, K., Ruat, M., Traiffort, E., 2005. Analysis of hedgehog interacting protein in the brain and its expression in nitric oxide synthase-positive cells. Neuroreport 16, 1959-1962.

Loulier, K., Ruat, M., Traiffort, E., 2006. Increase of proliferating oligodendroglial progenitors in the adult mouse brain upon Sonic Hedgehog delivery in the lateral ventricle. Journal of Neurochemistry 98, 530-542.

Louvi, A., Grove, E.A., 2011. Cilia in the CNS: the quiet organelle claims center stage. Neuron 69, 1046-1060.

Machold, R., Hayashi, S., Rutlin, M., Muzumdar, M.D., Nery, S., Corbin, J.G., GritliLinde, A., Dellovade, T., Porter, J.A., Rubin, L.L., Dudek, H., McMahon, A.P., Fishell, G., 2003. Sonic hedgehog is required for progenitor cell maintenance in telencephalic stem cell niches. Neuron 39, 937-950.

Mas, C., Ruiz i Altaba, A., 2010. Small molecule modulation of HH-GLI signaling: current leads, trials and tribulations. Biochemical Pharmacology 80, 712-723.

Masdeu, C., Bernard, V., Faure, H., Traiffort, E., Ruat, M., 2007. Distribution of Smoothened at hippocampal mossy fiber synapses. Neuroreport 18, 395-399. 
May, S.R., Ashique, A.M., Karlen, M., Wang, B., Shen, Y., Zarbalis, K., Reiter, J., Ericson, J., Peterson, A.S., 2005. Loss of the retrograde motor for IFT disrupts localization of Smo to cilia and prevents the expression of both activator and repressor functions of Gli. Developmental Biology 287, 378-389.

Milenkovic, L., Scott, M.P., Rohatgi, R., 2009. Lateral transport of Smoothened from the plasma membrane to the membrane of the cilium. The Journal of Cell Biology 187, 365-374.

Palma, V., Lim, D.A., Dahmane, N., Sanchez, P., Brionne, T.C., Herzberg, C.D., Gitton, Y., Carleton, A., Alvarez-Buylla, A., Ruiz i Altaba, A., 2005. Sonic Hedgehog controls stem cell behavior in the postnatal and adult brain. Development 132, 335-344.

Parathath, S.R., Mainwaring, L.A., Fernandez, L.A., Campbell, D.O., Kenney, A.M., 2008. Insulin receptor substrate 1 is an effector of sonic hedgehog mitogenic signaling in cerebellar neural precursors. Development 135, 3291-3300.

Pascual, O., Traiffort, E., Baker, D.P., Galdes, A., Ruat, M., Champagnat, J., 2005. Sonic hedgehog signalling in neurons of adult ventrolateral nucleus tractus solitarius. European Journal of Neuroscience 22, 389-396.

Petralia, R.S., Schwartz, C.M., Wang, Y.X., Mattson, M.P., Yao, P.J., 2011. Subcellular localization of patched and smoothened, the receptors for sonic hedgehog signaling, in the hippocampal neuron. The Journal of Comparative Neurology 519, 3684-3699.

Pritchard, J.I., Olson, J.M., 2008. Methylation of PTCH1, the Patched-1 gene, in a panel of primary medulloblastomas. Cancer Genetics and Cytogenetics 180, 47-50.

Putoux, A., Thomas, S., Coene, K.L., Davis, E.E., Alanay, Y., Ogur, G., Uz, E., Buzas, D., Gomes, C., Patrier, S., Bennett, C.L., Elkhartoufi, N., Frison, M.H., Rigonnot, L. Joye, N., Pruvost, S., Utine, G.E., Boduroglu, K., Nitschke, P., Fertitta, L., ThauvinRobinet, C., Munnich, A., Cormier-Daire, V., Hennekam, R., Colin, E., Akarsu, N.A., Bole-Feysot, C., Cagnard, N., Schmitt, A., Goudin, N., Lyonnet, S., EnchaRazavi, F., Siffroi, J.P., Winey, M., Katsanis, N., Gonzales, M., Vekemans, M. Beales, P.L., Attie-Bitach, T., 2011. KIF7 mutations cause fetal hydrolethalus and acrocallosal syndromes. Nature Genetics 43, 601-606.

Riobo, N.A., Manning, D.R., 2007. Pathways of signal transduction employed by vertebrate Hedgehogs. Biochemical Journal 403, 369-379.

Rohatgi, R., Milenkovic, L., Corcoran, R.B., Scott, M.P., 2009. Hedgehog signal transduction by Smoothened: pharmacologic evidence for a 2-step activation process. Proceedings of the National Academy of Sciences 106, 3196-3201.

Rohatgi, R., Milenkovic, L., Scott, M.P., 2007. Patched1 regulates Hedgehog signaling at the primary cilium. Science $317,372-376$

Roper, R.J., Baxter, L.L., Saran, N.G., Klinedinst, D.K., Beachy, P.A., Reeves, R.H., 2006 Defective cerebellar response to mitogenic Hedgehog signaling in Down [corrected] syndrome mice. Proceedings of the National Academy of Sciences 103, 1452-1456.

Rosenbaum, J.L., Witman, G.B., 2002. Intraflagellar transport. Nature Reviews 3, $813-825$.

Roudaut, H., Traiffort, E., Gorojankina, T., Vincent, L., Faure, H., Schoenfelder, A., Mann, A., Manetti, F., Solinas, A., Taddei, M., Ruat, M., 2011. Identification and mechanism of action of the acylguanidine MRT-83, a novel potent Smoothened antagonist. Molecular Pharmacology 79, 453-460.

Rudin, C.M., Hann, C.L., Laterra, J., Yauch, R.L., Callahan, C.A., Fu, L., Holcomb, T., Stinson, J., Gould, S.E., Coleman, B., LoRusso, P.M., Von Hoff, D.D., de Sauvage, F.J., Low, J.A., 2009. Treatment of medulloblastoma with hedgehog pathway inhibitor GDC-0449. New England Journal of Medicine 361, 1173-1178.

Ruiz i Altaba, A., Mas, C., Stecca, B., 2007. The Gli code: an information nexus regulating cell fate, stemness and cancer. Trends in Cell Biology 17, 438-447.

Scales, S.J., de Sauvage, F.J., 2009. Mechanisms of Hedgehog pathway activation in cancer and implications for therapy. Trends in Pharmacological Sciences 30, 303-312.

Sehgal, R., Sheibani, N., Rhodes, S.J., Belecky Adams, T.L., 2009. BMP7 and SHH regulate Pax2 in mouse retinal astrocytes by relieving TLX repression. Developmental Biology 332, 429-443.

Simpson, F., Kerr, M.C., Wicking, C., 2009. Trafficking, development and Hedgehog. Mechanisms of Development 126, 279-288.
Spassky, N., Han, Y.G., Aguilar, A., Strehl, L., Besse, L., Laclef, C., Ros, M.R., GarciaVerdugo, J.M., Alvarez-Buylla, A., 2008. Primary cilia are required for cerebellar development and Shh-dependent expansion of progenitor pool. Developmental Biology 317, 246-259.

Stipursky, J., Romao, L., Tortelli, V., Neto, V.M., Gomes, F.C., 2011. Neuron-glia signaling: Implications for astrocyte differentiation and synapse formation. Life Sciences 89, 524-531.

Suh, H., Deng, W., Gage, F.H., 2009. Signaling in adult neurogenesis. Annual Review of Cell and Developmental Biology 25, 253-275.

Takeda, S., Yonekawa, Y., Tanaka, Y., Okada, Y., Nonaka, S., Hirokawa, N., 1999 Left-right asymmetry and kinesin superfamily protein KIF3A: new insights in determination of laterality and mesoderm induction by kif3A-/- mice analysis. Journal of Cell Biology 145, 825-836.

Taschner, M., Bhogaraju, S., Vetter, M., Morawetz, M., Lorentzen, E., 2011 Biochemical mapping of interactions within the intraflagellar transport (IFT) B core complex: IFT52 binds directly to four other IFT-B subunits. The Journal of Biological Chemistry 286, 26344-26352.

Town, T., Breunig, J.J., Sarkisian, M.R., Spilianakis, C., Ayoub, A.E., Liu, X., Ferrandino, A.F., Gallagher, A.R., Li, M.O., Rakic, P., Flavell, R.A., 2008. The stumpy gene is required for mammalian ciliogenesis. Proceedings of the National Academy of Sciences 105, 2853-2858.

Traiffort, E., Angot, E., Ruat, M., 2010. Sonic Hedgehog signaling in the mammalian brain. Journal of Neurochemistry 113, 576-590.

Traiffort, E., Charytoniuk, D., Watroba, L., Faure, H., Sales, N., Ruat, M., 1999. Discrete localizations of hedgehog signalling components in the developing and adult rat nervous system. European Journal of Neuroscience 11 3199-3214.

Traiffort, E., Charytoniuk, D.A., Faure, H., Ruat, M., 1998. Regional distribution of Sonic Hedgehog, patched, and smoothened mRNA in the adult rat brain. Journal of Neurochemistry 70, 1327-1330.

Traiffort, E., Dubourg, C., Faure, H., Rognan, D., Odent, S., Durou, M.R., David, V. Ruat, M., 2004. Functional characterization of Sonic Hedgehog mutations associated with holoprosencephaly. The Journal of Biological Chemistry 279 42889-42897.

Traiffort, E., Moya, K.L., Faure, H., Hassig, R., Ruat, M., 2001. High expression and anterograde axonal transport of aminoterminal Sonic Hedgehog in the adult hamster brain. European Journal of Neuroscience 14, 839-850.

Trazzi, S., Mitrugno, V.M., Valli, E., Fuchs, C., Rizzi, S., Guidi, S., Perini, G. Bartesaghi, R., Ciani, E., 2011. APP-dependent up-regulation of Ptch1 underlies proliferation impairment of neural precursors in Down syndrome. Human Molecular Genetics 20, 1560-1573.

Varjosalo, M., Taipale, J., 2008. Hedgehog: functions and mechanisms. Genes and Development 22, 2454-2472.

Wallace, V.A., Raff, M.C., 1999. A role for Sonic Hedgehog in axon-to-astrocyte signalling in the rodent optic nerve. Development 126, 2901-2909.

Wong, S.Y., Seol, A.D., So, P.L., Ermilov, A.N., Bichakjian, C.K., Epstein Jr., E.H., Dlugosz, A.A., Reiter, J.F., 2009. Primary cilia can both mediate and suppress Hedgehog pathway-dependent tumorigenesis. Nature Medicine 15 1055-1061.

Yauch, R.L., Dijkgraaf, G.J., Alicke, B., Januario, T., Ahn, C.P., Holcomb, T., Pujara, K., Stinson, J., Callahan, C.A., Tang, T., Bazan, J.F., Kan, Z., Seshagiri, S., Hann, C.L., Gould, S.E., Low, J.A., Rudin, C.M., de Sauvage, F.J., 2009. Smoothened mutation confers resistance to a Hedgehog pathway inhibitor in medulloblastoma. Science 326, 572-574.

Yin, Y., Bangs, F., Paton, I.R., Prescott, A., James, J., Davey, M.G., Whitley, P., Genikhovich, G., Technau, U., Burt, D.W., Tickle, C., 2009. The Talpid3 gene (KIAA0586) encodes a centrosomal protein that is essential for primary cilia formation. Development 136, 655-664.

Yoshimura, K., Kawate, T., Takeda, S., 2011. Signaling through the primary cilium affects glial cell survival under a stressed environment. Glia 59, 333-344.

Zhao, C., Deng, W., Gage, F.H., 2008. Mechanisms and functional implications of adult neurogenesis. Cell 132, 645-660. 